University of Nebraska - Lincoln

DigitalCommons@University of Nebraska - Lincoln

Sociology Department, Faculty Publications

Sociology, Department of

8-1999

\title{
Meaning and Measurement: Reconceptualizing Measures of the Division of Household Labor
}

\author{
Joan E. Twiggs \\ University of Connecticut \\ Julia McQuillan \\ University of Nebraska-Lincoln, jmcquillan2@Unl.edu \\ Myra Marx Feree \\ University of Connecticut, mferree@ssc.wisc.edu
}

Follow this and additional works at: https://digitalcommons.unl.edu/sociologyfacpub

Part of the Sociology Commons

Twiggs, Joan E.; McQuillan, Julia; and Marx Feree, Myra, "Meaning and Measurement: Reconceptualizing Measures of the Division of Household Labor" (1999). Sociology Department, Faculty Publications. 32. https://digitalcommons.unl.edu/sociologyfacpub/32

This Article is brought to you for free and open access by the Sociology, Department of at DigitalCommons@University of Nebraska - Lincoln. It has been accepted for inclusion in Sociology Department, Faculty Publications by an authorized administrator of DigitalCommons@University of Nebraska - Lincoln. 


\title{
Meaning and Measurement: Reconceptualizing Measures of the Division of Household Labor
}

\author{
Joan E. Twiggs, ${ }^{1}$ Julia McQuillan, ${ }^{2}$ and Myra Marx Ferree ${ }^{1}$ \\ ${ }^{1}$ Department of Sociology U-68, University of Connecticut, 344 Mansfield Road, Storrs, CT 06269 \\ ${ }^{2}$ Department of Sociology, University of Nebraska-Lincoln, 711 Oldfather Hall, Lincoln, NE 68588
}

\begin{abstract}
This article argues that task-specific measures of the division of household labor form a gender hierarchy that reflects dimensions of meaning in the organization of household work. We contrast these measures to the commonly used time-share and Likert scale measures, which assume all tasks are interchangeable. Using Guttman scaling, we test the unidimensionality of this task hierarchy. Using odds ratios, we measure relationships between specific tasks, and using logistic regression, we see differences in correlates of husbands' participation by task and interrelationships among tasks that persist, controlling for gender ideology and socioeconomic factors. This work should encourage development of measures of change in the segregation of household tasks by gender.
\end{abstract}

Keywords: couples, domestic labor, division of household labor, gender theory, measuring housework, husbands

Many studies have found that women, even when employed, remain responsible for housework (England \& Farkas, 1986; Lennon \& Rosenfield. 1994). The actual division of housework by gender has been less clearly conceptualized and measured (Blair \& Lichter, 1991). Even though researchers no longer assume that all housework is "women's work" by definition, the possibility that specific tasks might change gender assignment - the way specific occupations have done-is not explicitly addressed in the literature. Investigating the gender meanings of specific tasks has largely been left to qualitative research (DeVault, 1991; Hochschild, 1989).

We suggest several different quantitative approaches to measuring the similarity and differences in household tasks, and we show that the factors that explain husbands' participation differ, depending on the task. We argue that such measures of task hierarchy can complement qualitative research by improving our understanding of both where and why change already is occurring and what task-specific resistances and obstacles to greater participation by husbands exist. Our argument is grounded in the literatures of the gender perspective and occupational sex segregation.

\section{Literature Review}

In the past decade, the literature on the division of household labor has increasingly become guided by the awareness that gender itself plays an im- 
portant role. Previous work has clearly established that despite entry into the labor force in increasing proportions, wives remain disproportionately responsible for household maintenance (Baxter, 1992; Blair \& Johnson, 1992; Ross, 1987; Shelton \& John, 1993). Moreover, gender-neutral, resourcebased approaches, although important, are not sufficient to explain the unequal division of labor (Ferree, 1990; Thompson \& Walker, 1989). The gender perspective offers one explanation for the continuing lopsided division of household labor. From this perspective, performing housework certainly produces material results such as clean clothes and hot meals, but the gendered division of household labor also produces proper gender relations (e.g., Blain, 1994; DeVault, 1991; Fenstermaker Berk, 1985; South \& Spitze, 1994) and social identities (Fraser, 1989). Researchers in this perspective argue that all work, including work done at home without pay, is "dual aspect activity" (Fraser) and takes on symbolic meaning, part of which is gendered meaning. From this perspective, both labormarket work and household work are divided less from considerations of skill, time, or talent, than from efforts to establish boundaries between men's and women's work. Such boundaries affirm and reproduce masculinity and femininity, and doing the sort of work defined as inappropriate for one's gender produces demands for accountability or justifications for why such a transgression of normative expectations is warranted (Gerson \& Peiss, 1985: West \& Zimmerman, 1987).

On the one hand, gender boundaries such as those that structure the paid labor market are constructed, in part, through the labeling of specific skills and interests as appropriate for men or for women (Acker, 1990; Reskin, 1993; West \& Zimmerman, 1987). On the other hand, the gender division of labor is not only the outcome of the systematic creation of differential sets of skills between men and women. Women may be the cooks at home, but men are disproportionately the chefs and short-order cooks in the paid labor market. Who does what work, whether or not for pay, also reflects the need to produce gender as a signification of power and difference in a specific relationship or institutional context. For example, South and Spitze's (1994) analysis of how men in different marital statuses do different amounts of housework suggests that when and how household labor is performed carries gender meanings and does not only reflect the individual's aptitude or skill, however gender specific the latter might be.
When we assume that housework is partly about constructing "proper" gender relations, it follows that differences in task assignment may express differences in norms of "gender accountability" (West \& Zimmerman, 1987). Researchers working from a gender perspective question why wives, even those sharing wage labor, remain responsible for routine and repetitive or core household tasks, $70 \%-90 \%$ of all household labor time. Hence, these researchers focus on the negotiations and meanings embedded in household labor that sustain household inequalities (Coltrane, 1996; Fenstermaker Berk, 1985; Ferree, 1991 ; Hochschild, 1989: Hood, 1983; Potuchek, 1997).

Qualitative work on the division of household labor has been more adept than quantitative research at probing the construction of the meaning of specific chores. In addition to methodological differences, there are different emphases on research questions. Qualitative work focuses more on analyzing the dimensions of the work itself and its relation to making family (e.g. Coltrane, 1989; DeVault, 1991: Hood, 1983; Pahl, 1989; Tichenor, 1996) and has led the way in looking at task performance as the construction of notions of masculinity and femininity. Like case studies of occupations that reflect a perspective of doing gender (Hall, 1993; Pierce, 1995), case studies of the division of household labor have examined how the dimensions of tasks are embedded in the social construction of gender (DeVault, 1991). Indeed, qualitative research has suggested that an order and hierarchy might exist among household tasks, and the performance of certain tasks might make more probable the performance of others (Coltrane, 1989).

Picking up on this concern, some quantitative researchers such as Blair and Lichter (1991) have argued that a more complete explanation of the division of household labor needs to offer theoretical accounts of "the kinds of work that men and women do, [as much as accounts] about how much work they actually do" (p. 110). However, most quantitative research has focused only on the amount of housework husbands and wives do. To answer the question of how much housework husbands and wives do, researchers have used measures that accumulate time, tasks, or both. Such measures of time spent doing housework are useful. They enable researchers to compare and contrast the increase in men's household labor with the increase in women's participation in the labor force. But just as measuring labor-force participation alone without attention to gender segregation in the paid work force 
only provides a partial picture of change in labor markets, measuring time spent doing housework without attention to specific tasks can be misleading. Time alone does not tell the whole story. The same amount of time can be spent performing segregated tasks, working cooperatively on all tasks, or doing counter-stereotypical chores (Blair \& Lichter, 1991; Fenstermaker Berk, 1985). Moreover, certain outcomes - marital satisfaction, personal wellbeing, or perceived fairness - may depend as much on the specific task-based division of household labor as on the total time spent in housework (Ferree, 1991; Greenstein, 1996).

The quantitative measures in common use sum the amount of overall time spent performing housework (Lennon \& Rosenfield, 1994) and use Likerttype scales of tasks to assess who is more responsible for tasks (Ferree, 1991; Huber \& Spitze, 1983; Spitze, 1986). This approach implicitly assumes that increases in men's household labor will flow equally to any and all tasks. Indeed, if husbands behaved in the way that both Likert-type scale measurement and time summation methods assume, we might expect them to be represented in equal proportions across all female-typed tasks and all possible combinations of tasks.

A random distribution, however, is not what the research reveals. In major studies of the division of household labor that employ some form of task measurement, husbands demonstrate patterned participation in core household jobs (Blair \& Lichter, 1991; Blood \& Wolfe, 1960; Fenstermaker Berk, 1985; Ferree, 1991; Huber \& Spitze, 1983; Robinson, 1988; South \& Spitze, 1994). Studies of who performs the core household tasks of dishwashing, doing laundry, grocery shopping, general house cleaning, and preparing meals, indicate that husbands are less likely to do the laundry, for example, than to do the dishes. This ordering of tasks along a dimension from the least female dominated to the most female dominated is a pattern that is lost in Likert-type, summed-scale operationalizations, and the information it contains is, therefore, implicitly treated as unmeaningful. Yet, these studies show that husbands' participation in doing dishes and grocery shopping is consistently greater than in the other core household tasks.

Sex typing is a concept commonly used to capture the degree of a single sex's participation in an occupation. The literature of occupational sex segregation defines sex typing conceptually as "any outcome in which members of one group are concentrated or excluded" (Reskin, 1993, p. 244). This concept has also been applied to household work. Blair and Lichter (1991) calculate the index of dissimilarity, a measure often used to assess occupational sex segregation, to determine the extent to which the husbands in their sample would have to reallocate their family hours spent in household tasks to achieve task integration. In most studies of the division of household labor, however, the concept has been used somewhat loosely. Although much research on the division of household labor refers to tasks as sex typed, few studies are explicit about the criteria they use to apply the label "female sex typed" to certain chores. Moreover, for the most part, household tasks have been characterized as only male or female (but see Fenstermaker Berk, 1985, for an exception), thus assuming a single gender threshold that divides male- from femaletyped tasks. Once on the female side of the threshold, tasks are not differentiated further. Doing the dishes is counted as having the same meaning for the gender division of household labor as cooking dinner. Some researchers include a gender-neutral category (Blair \& Johnson, 1992; Lennon \& Rosenfield, 1994; South \& Spitze, 1994), and others do not (Brines, 1993; Ferree, 1991).

The use of subjective, a priori assessments of sex type makes it difficult to compare findings across studies and has resulted in placing the same task in different categories. Blair and Johnson (1992) categorize grocery shopping as gender neutral, but South and Spitze (1994) count it as a female-typed task, even though they also have a gender-neutral category and use the same national data set (the National Survey of Families and Households). Such a lack of clear operationalization hampers analysis of changes in gender boundaries. Like an occupation, a household task (such as grocery shopping) may change its sex type or the extent of its segregation over time. However, without more clarity and consistency in operationalizing sex type for household tasks, quantitative measurement of specific changes is blocked. Macro-level stability in the proportion of household labor that is done by men is consistent with the gender redefinition and resegregation of specific tasks, just as increasing, decreasing, or stable levels of participation in the labor force by women is consistent with stable or changing patterns of occupational segregation.

In this regard, the literature on occupational sex segregation provides a useful corrective. Studies of occupational sex segregation operationalize cut-off points for calling a specific job or occupation sex typed. These cut-off points are specific enough to 
measure the degree of change over time in the extent of sex segregation, not only in the labor market as a whole but in specific occupations or clusters of occupations (e.g., Reskin \& Roos, 1990). The gender barriers and tipping points specific to particular occupations can be studied, rather than assuming that increases in female labor-force participation flow equally into all types of work. These cut-off points for typing an occupation as female or male are admittedly arbitrary and do vary. Some researchers use $75 \%$ or $80 \%$ of one sex to define the categories. Others use a percentage-point deviation from the sexes' representation in the labor force (Reskin, 1993; Williams \& Villemez, 1993).

Research on the sex typing of occupations also has focused on the mechanisms of reproducing and rationalizing sex typing in specific occupations and clusters of related occupations (Cohn, 1985; Hall, 1993; Pierce, 1995). Reskin and Roos (1990) have looked at how occupations undergoing gender integration are changing in other dimensions, for example in autonomy, rewards, mechanization, or specialization. Thus the literature on occupational sex segregation orients researchers not only to measuring the extent of sex segregation, but also to asking questions about how sex typing is constructed in relation to other job characteristics and to recognizing changes in occupational sex type.

The ability to identify points where changes are occurring does not necessarily make researchers sanguine about the overall prospects for occupational integration. As Reskin and Roos (1990) point out, evidence of increasing gender integration in a specific occupation may, in fact, be an indication that it is in the early stages of changing its sex type, and many occupations appear to welcome women only when the conditions and rewards of the work are declining. Conversely, as Williams (1989) has pointed out, men's entry into what was conventionally women's work often means moving men into the best jobs in that occupational category and offering them more authority and status. Applying an approach of occupational sex segregation to the division of household labor implies attempting to identify which tasks are or are becoming less female sex typed and what characteristics of the work or the workers tend to predict men's greater participation in these chores rather than others.

In summary, both qualitative and quantitative studies find that husbands' household labor is patterned in ways that are analogous to sex segregation in the labor market. Qualitative studies have explored these patterns and their meaning for some of the tasks most embedded (DeVault, 1991) in family life, but these studies are difficult to generalize beyond their particular nonrepresentative samples. Quantitative studies are beginning to recognize more differentiation by introducing categories like gender-neutral tasks, but it is hard to tell if such changes reflect differences in who is now doing the work or in the cultural meaning the work carries (manifested implicitly in the researchers' subjective judgment that sex type has changed). Although quantitative researchers have acknowledged the differences between measures of time and tasks in the division of household labor, they have scarcely begun to tap the potential of task measures to give insights into the meaning of men's participation in housework.

We begin to elucidate distinctions in the meaning of tasks identified in qualitative work that used small samples by using a larger, more generalizable sample. First, we look at how five common household tasks are sex typed in our data. We then address three research questions: Do these five common household tasks form a gender hierarchy? Is male participation in tasks bundled so that working in more highly female sex-typed household tasks predicts working in less sex-typed ones? Do characteristics of male household workers distinguish those who work in female-dominated tasks from those who do not?

\section{Analysis}

Our analyses fall into two broad groups. First, we examine the interrelationships among the tasks themselves. We look for patterns of sex segregation based on a possible gender hierarchy among the core tasks or other types of coherence (or stickiness) among specific sets of tasks. We do this by testing whether the data fit a Guttman scale and by evaluating odds ratios between tasks. Then, using logistic regression, we turn to an analysis of the characteristics that predict greater or lesser husband participation in specific tasks. Characteristics are divided into two general categories taken from the research literature on the division of household labor. Rational pragmatic characteristics derive from the economic approach to explaining the division of household labor exemplified by Becker (1991). Becker suggests that men participate in domestic chores less than women because of the economic reality that men earn more money and work longer hours. A logical strategy for couples, therefore, is for wives to spe- 
cialize more in domestic labor and for husbands to specialize more in paid labor. Additional rational explanations of the division of labor are total time available (Coverman, 1985) and specific times available because of schedules (Presser, 1994; Staines \& Pleck, 1983). Support for these rational explanations for the division of labor is limited. (See Ferree, 1990, or Thompson \& Walker, 1989, for reviews of this literature.) The more rational and pragmatic characteristics of husbands predict their task participation, the less support there is for a gendered explanation of husbands' participation.

Given the limits of rational and pragmatic explanations, there has been increasing focus on nonrational and normative explanations of the gender division of domestic labor, particularly among twoearner couples (Hertz, 1986; Tichenor, 1996). Initial studies emphasized gender attitudes as a probable cause of the continuing imbalance between the domestic labor of husbands and wives. However, in studies using absolute or relative measures of time, attitude variables have been weak and inconsistent predictors of the division of labor (England \& Farkas, 1986). In addition to direct questions assessing gender attitudes, age and education are also used as proxies for attitudes. Younger and better-educated husbands are assumed to have less sexist beliefs, which should predict greater participation. In addition, husbands who enjoy housework or who are willing to admit that they enjoy housework should be more likely to engage in it.

It is impossible with cross-sectional data to determine the causal ordering of attitudes and behaviors. Social-psychological research suggests that, contrary to common belief, behavior often precedes attitudes. In other words, individuals are more likely to bring their attitudes in line with their behavior than the reverse (Fishbein \& Ajzen, 1975). However, for our purposes, the direction of causation is irrelevant because either ordering supports the argument that tasks differ in meaning. Given that our thesis is that these tasks differ, we expect beliefs to differentiate participation in tasks. Tasks that are more strongly sex typed as female and require men to be more accountable for their gender transgression may either require or generate more egalitarianism on men's part (McQuillan \& Ferree, 1997). Conversely, in tasks where female sex typing is less, such as doing the dishes, a less-gendered attitude (such as enjoyment of the task itself) may be either the cause or the effect of participation.

In summary, if nonrational and normative characteristics of husbands are better predictors of task participation than rational and pragmatic character- istics, there is support for the gender interpretation of the division of household labor. If these characteristics predict their differential participation in tasks, there is strong support for our interpretation of a gender hierarchy of tasks.

\section{Data and Methods}

The data set consists of a representative sample of two-earner households in Connecticut. Both husbands and wives in 382 couples were interviewed by telephone in the spring of 1989 . Wives were selected first for interviews $(n=550$, with a response rate of $62 \%$ ). Husbands completed interviews in $70 \%$ of the cases in which wives' interviews were obtained. Comparison of couples in which both partners were interviewed with those in which only the wife responded showed only two significant differences. When both partners responded, wives report happier marriages and a higher level of education for both themselves and their spouses. The sample is clearly not generalizable to the entire United States. Like the population of Connecticut, the sample is more White (95\%) and Catholic (51\%) than the nation as a whole, and the median total family income is relatively high $(\$ 62,000)$, even for dual-earner couples, themselves a disproportionately affluent group. (See Ferree, 1991, for a more detailed description of the sample.)

\section{Measures of the Division of Labor}

Participation in routine, ongoing household chores was assessed in these data by a self-report Likert-type response scale. Both husbands and wives were asked: "Certain things have to be done in every household. Could you tell me who does the following things in your family? It might be always you, or usually you, both you and your wife about equally, usually your wife, or always your wife. First of all, who prepares regular meals for your household [HMEALS]; cleans up after meals [HCLEAN]; shops for food for the family [HGROC]; pays the monthly bills [HBILLS]; does the regular housecleaning [HCLEAN]; does the laundry [HLAUND]?" Each variable was measured on a scale from 1 (wife always) to 5 (husband always). We operationalize the husband's doing the chore by a response of 3 (about equally) or higher. (See Table 1.) Table 1 also shows the proportion of husbands taking responsibility for each task. (A score of 4 or higher indicates that the husband usually or always does the task.) Following Ferree (1991), we drop the 
Table 1. Husbands' Participation and Sex Type of Tasks

\begin{tabular}{lccccc}
\hline & $\begin{array}{c}\text { Preparing } \\
\text { Meals }\end{array}$ & $\begin{array}{c}\text { Doing } \\
\text { Laundry }\end{array}$ & $\begin{array}{c}\text { Cleaning } \\
\text { House }\end{array}$ & $\begin{array}{c}\text { Shopping for } \\
\text { Groceries }\end{array}$ & $\begin{array}{c}\text { Doing } \\
\text { Dishes }\end{array}$ \\
\hline Percentage of husbands who participate (1989) & 25 & 27 & 39 & 41 & 59 \\
Percentage of husbands responsible (1989) & 7 & 8 & 6 & 13 & 19 \\
Percentage participating who are wives (1989) & 78 & 77 & 70 & 70 & 59 \\
\hline
\end{tabular}

bill-paying measure from the scale because theory and a low level of correlation of bill paying to the remainder of the scale suggest that it does not tap the same underlying dimension. (See also Pahl, 1989.)

We consider a task male sex typed if $75 \%$ or more of the people doing the task are husbands and female sex typed if $75 \%$ or more doing the task are wives. Although this is an arbitrary line, it has the advantage of being midway between the $70 \%$ and $80 \%$ cut-off points preferred by occupational researchers and could become a shared standard (like the equally arbitrary .05 level of statistical significance). Using husbands' reports to determine husbands' participation and wives' reports to determine wives' participation, we determine the total number of people participating in a given task (e.g., all husbands who report participation and all wives who report participation). We then find the percentage of those participating in the task who are wives.

Table 1 shows that by our formal criterion of $75 \%$ or more of wife participation, only preparing meals and doing laundry were clearly female sex typed in our sample. However, few men (fewer than 10\%) took responsibility for housecleaning, which is no more than the percentage who prepared meals or did laundry. Doing dishes is the most clearly gender-integrated task; "only" $60 \%$ of those who do dishes are wives.

We now evaluate whether husbands' participation varies meaningfully between more and less strongly female sex-typed forms of work. We expect to find that husbands who do more strongly sex-typed chores will also do more chores overall. This suggests that there is more than one threshold of gender appropriateness to cross. Because qualitative research suggests that a major barrier to husband participation in domestic tasks is the gendered meaning attributed to types of labor, we hypothesize that husbands who do the most gendered task-preparing meals-would have no barrier to doing tasks that are lower on the gender hierarchy.

We also hypothesize that the mix of household and husband characteristics associated with husbands' participation in housework will vary with the task. Because some tasks are more strongly sex typed than others, the relative role of beliefs in conventional gender arrangements should vary by task. Doing dishes, a task which has a less evident sex type, would not seem to challenge gendered expectations for appropriate male behavior and thus may not be strongly associated with normative or ideological factors. Alternatively, the fact that doing dishes is less sex typed in the aggregate may suggest that male participation in this task is the behavioral expression of more egalitarian gender norms in some households, leading ideological factors to have a stronger association with this task than with others. Conversely, the most clearly sex-typed chore-preparing meals-might be thought to have a predominantly ideological set of related factors, making husbands' participation in it reflect a deliberate challenge to gender norms. Alternatively, it may not be well related to ideological factors because virtually all husbands may accept the appropriateness of wives doing at least this work, even if they endorse sharing housework in principle.

In order to explore the meanings that different tasks carry in the division of labor, we look at the characteristics of husbands and households that are differentially associated with participation in each of the five tasks. We divide these characteristics into what are generally considered rational or pragmatic explanations for participation (time demands on husband and wife, the number of children, work schedules) and normative explanations (education, gender attitudes, and conflict over housework). The variables used in that analysis are described below.

\section{Measures of Rational and Pragmatic Predictors}

Our first measure is husbands' employment schedule. We compare husbands who have employment schedules that make them more available for most tasks (before 4 P.M.) with those who have schedules that make them less available. A dummy variable, created from a series of questions about the average time the husband leaves for work and returns from work measures if he typically arrives home before 4 P.M.

We assume that more time in employment and with children leaves less time for task participation. 
We use the husband's report of the wife's paid labor time because this perspective assumes that it is the husband's perception of his wife's available time that will influence his participation. Husbands were asked: "How many hours does your wife spend in an ordinary week (on her job or on all her jobs together)? How many hours do you spend in an ordinary week on your job?" In order to measure child- care time, husbands were asked: "On average, on days when you are working, about how many hours do you spend actively taking care of or doing things with your children? How much time on days when you're not working?" Responses were combined to form a measure of hours per week of child care.

We use a simple measure for the concept of relative economic resources-the wife's percentage of the couple's income-to capture a possible tradeoff between earnings provided and husband's task participation.

\section{Measures of Normative Factors}

Age is measured in simple 1-year increments, ranging from 21 to 68 years.

Education is measured in degrees earned: less than high school, high school degree, some college, B.A., more than a B.A.

Using husband's responses to a statement about housework, we measured their attitudes about housework. Husbands were asked if they "strongly agree, agree, disagree, strongly disagree" with the following statement: "Housework is basically enjoyable work."

We divide gender attitudes into two related concepts: role appropriateness of housework for husbands and wives, in general, and feelings of conflict and cooperation about housework in the individual relationship. Qualitative work finds sharply different consequences of abstract beliefs about roles and more personally applicable and emotionally loaded concerns about-doing housework, including criticism of husbands by wives or feelings by husbands that wives are not living up to their domestic expectations (e.g., Hochschild, 1989; Mahoney, 1995; Potuchek, 1997). We measure abstract gender appropriateness with four items: whether housework is the wife's responsibility, regardless of her paid work status [HWRESP]; whether willingness to do household chores is an important quality of being a good husband [HROLE2R]; the extent to which husbands think that "men's work" and "women's work should be separate [HROLE3]; and how much husbands value equally sharing housework [HVAL5R].
The affectively loaded norms for the management of housework by the individual couple were tapped with three items. Husbands were asked if they strongly agreed, agreed, disagreed, strongly disagreed with: "You never seem to be able to do household chores the way your wife wants them done" [HCRITIC]," "you usually do certain household chores without your wife needing to ask" [HAIDR, reversed]," and "since people often feel differently about similar situations, I'll read you a short list of feelings and ask you, when you think about the amount of housework your wife does, do you usually, sometimes, or never feel pleased?" [HFEEL2].

These seven items were factor analyzed (principal components varimax rotation). The eigenvalue for the gender attitudes factor is 2.12; for the conflict factor it is 1.18. None of the gender attitude variables has a loading over .30 on the conflict factor, but one of the conflict variables, (HAIDR-doing household chores without being asked) has a high loading on both factors (.43 on gender attitudes, .56 on the conflict factor). These two factors explain $47 \%$ of the variance in the seven items. Factor scores for each concept were constructed, each with a mean of zero and standard deviation of 1 . The alpha reliability for the gender items is .61; for the conflict items it is .32. The latter is a low reliability measure if we were simply combining items in an additive scale, but because we use the factor regression scores, we are less concerned with the reliability coefficient.

\section{Results}

\section{Patterns of Husbands' Participation}

We first examine the relationship between the specific tasks that husbands do and the number of tasks that they do to see if doing certain tasks implies crossing a threshold that makes doing other chores more probable. Are husbands who do at least one highly female sex-typed task likely to do more chores overall than husbands who do at least one lower female sex-typed task? Borrowing from epidemiology, we statistically test these patterns by odds ratio analyses where the outcome is doing more than one household task and the risk factors are the performance or nonperformance of each specific household task.

For husbands who do only one task, what task are they most likely to do? For half $(48 \%)$ of these low participators $(n=92)$ that task is doing the dishes. This suggests that it has the lowest threshold blocking participation. In contrast, a quarter (26\%) 
of the low participators do only grocery shopping, $15 \%$ do only cleaning, $9 \%$ only laundry, and $4 \%$ only meal preparation. Thus it is likely that a low participator does dishes and unlikely that he prepares meals. If we consider the moderate participators (those who at least share three tasks, $n=70$ ), a similar pattern of preferred tasks is evident. Virtually all do dishes (86\%), two thirds at least share grocery shopping (66\%) and house-cleaning (64\%), and fewer than half include meals $(45 \%)$ or laundry (468) among the chores with which they at least help. Overall, only 13 husbands report participating in all five core tasks, and of the 42 high participators who do four of the five tasks, $29 \%$ do not prepare meals, 268 do not do laundry, and $22 \%$ do not do housecleaning, but only $10 \%$ do not do grocery shopping or dishes. Thus the ordering of chores is the same for low-, moderate-, and high-participation husbands. Doing dishes appears to be a husband's port of entry into sharing. It is the first chore to be taken up, and it is added to rather than replaced by husbands who do more chores. Conversely, there is a high threshold for meal preparation. It is rarest for low-participation husbands to prepare meals, and even for husbands who share four of the five core tasks, preparing meals is the one task they are most likely to avoid.

Another way of looking at this pattern is that husbands who prepare meals (the most sex-typed task) are more likely than other husbands to do other chores. (See Table 2.) Many of them (76\%) also wash dishes, more than half shop for groceries $(57 \%)$ and clean $(56 \%)$, and some also do laundry $(43 \%)$. The ordering of tasks hierarchically means that nearly two thirds (64\%) of husbands who share doing laundry at least equally with their wives also share cleaning the house, but fewer than half of the husbands who share housecleaning also do laundry
(45\%). We can formalize this pattern by calculating the odds of doing more than one household task, given that a husband does a specific task. All of the odds ratios (see Table 2) are statistically significant at the .05 level. Clearly those who prepare meals are at a greater risk of doing more than one task than those doing any other task. (The odds are almost 18 times greater.) This analysis suggests that men who do the more sex-typed tasks also tend to do more tasks than men who do less sex-typed ones. These men add on, rather than substitute, more countersex-typed tasks for less counter-sex-typed tasks.

We can take the examination of the underlying pattern a step further by a specific test of the structure of the data, namely a classic Guttman scale. A Guttman scale is a unidimensional and cumulative measure that describes a hierarchy of attitudes or behaviors. When data fit a Guttman scale, each successive level encompasses the level preceding it. If, as the gender perspective suggests, performing some female-typed tasks requires husbands to transgress norms of gender accountability, the organization of these tasks can be seen as a series of steps or thresholds, and the pattern that results should fit a Guttman scale. Applying a Guttman scale provides two conceptual and methodological advantages. First, because a Guttman scale is hierarchical, describing a husband's numerical position on the scale does not, like the Likert model, imply interchangeability of tasks. Second, a Guttman scale can be used to predict the performance of specific household tasks. Knowing the step of the scale that the husband occupies provides information about the other tasks he performs. Because that information is summarized in the measure of scale position, qualitative distinctions may be modeled quantitatively.

We test for the presence of a Guttman scale at the cut-off point of 3 and above: husbands who at

Table 2. Percentages and Odds Ratios of Engaging in Other Chores for Husbands Doing a Particular Chore

\begin{tabular}{|c|c|c|c|c|c|}
\hline Chore & $\begin{array}{l}\text { Of Those } \\
\text { Preparing Meals, } \\
\text { What Percentage } \\
\text { Do Other Tasks? }\end{array}$ & $\begin{array}{c}\text { Of Those } \\
\text { Doing Laundry, } \\
\text { What Percentage } \\
\text { Do Other Tasks? }\end{array}$ & $\begin{array}{l}\text { Of Those } \\
\text { Cleaning House, } \\
\text { What Percentage } \\
\text { Do Other tasks? }\end{array}$ & $\begin{array}{c}\text { Of Those } \\
\text { Shopping for } \\
\text { Groceries, } \\
\text { What Percentage } \\
\text { Do Other Tasks? }\end{array}$ & $\begin{array}{c}\text { Of Those } \\
\text { Doing Dishes, } \\
\text { What Percentage } \\
\text { Do Other Tasks? }\end{array}$ \\
\hline Doing dishes & $76 \%$ & $70 \%$ & $77 \%$ & $66 \%$ & \\
\hline Shopping for groceries & $57 \%$ & $55 \%$ & $45 \%$ & & $53 \%$ \\
\hline Cleaning house & $56 \%$ & $64 \%$ & & $44 \%$ & $46 \%$ \\
\hline Doing laundry & $43 \%$ & & $45 \%$ & $37 \%$ & $32 \%$ \\
\hline Preparing meals & & $40 \%$ & $38 \%$ & $37 \%$ & $35 \%$ \\
\hline \multicolumn{6}{|l|}{ Odds of doing more } \\
\hline than this one chore & $17.8^{* *}$ & $8.2^{*}$ & $9.6^{*}$ & $4.4^{*}$ & $5.3^{*}$ \\
\hline$n$ engaged in the chore & 98 & 101 & 143 & 153 & 216 \\
\hline
\end{tabular}

${ }^{*} p<.05,{ }^{* *} p<.01$ 
Table 3. Guttlian Analysis of All Five Tasks in Five Steps

\begin{tabular}{|c|c|c|c|c|c|c|c|c|c|c|c|}
\hline \multirow[b]{2}{*}{$n$ of tasks } & \multicolumn{2}{|c|}{$\begin{array}{l}\text { Preparing } \\
\text { Meals }\end{array}$} & \multicolumn{2}{|c|}{$\begin{array}{l}\text { Doing } \\
\text { Laundry }\end{array}$} & \multicolumn{2}{|c|}{$\begin{array}{l}\text { Cleaning } \\
\text { House }\end{array}$} & \multicolumn{2}{|c|}{$\begin{array}{l}\text { Shopping for } \\
\text { Groceries }\end{array}$} & \multicolumn{2}{|c|}{$\begin{array}{l}\text { Doing } \\
\text { Dishes }\end{array}$} & \multirow[b]{2}{*}{$n$} \\
\hline & 0 & 1 & 0 & 1 & 0 & 1 & 0 & 1 & 0 & 1 & \\
\hline 5 & 0 & 13 & 0 & 13 & 0 & 13 & 0 & 13 & 0 & 13 & 13 \\
\hline 4 & 12 & 29 & 9 & 32 & 4 & 38 & 11 & 31 & 4 & 38 & 42 \\
\hline 3 & 38 & 32 & 37 & 30 & 24 & 43 & 24 & 46 & 10 & 59 & 70 \\
\hline 2 & 66 & 20 & 70 & 18 & 47 & 36 & 49 & 39 & 21 & 63 & 88 \\
\hline 1 & 88 & 4 & 82 & 8 & 72 & 13 & 68 & 24 & 46 & 43 & 92 \\
\hline 0 & 77 & 0 & 75 & 0 & 72 & 0 & 76 & 0 & 72 & 0 & 77 \\
\hline$n$ & 281 & 98 & 273 & 101 & 219 & 143 & 228 & 153 & 153 & 216 & 379 \\
\hline \multicolumn{10}{|c|}{ Percentage failing } & $58 \%$ & \\
\hline Errors & 0 & 85 & 9 & 56 & 28 & 49 & 39 & 24 & 81 & 0 & 371 \\
\hline$n$ & \multicolumn{2}{|c|}{379} & \multicolumn{2}{|c|}{374} & \multicolumn{2}{|c|}{362} & \multicolumn{2}{|c|}{381} & \multicolumn{2}{|c|}{369} & 379 \\
\hline
\end{tabular}

Note: The cutoff point is 3 (husband and wife at least share tasks equally). All the cases above the diagonal should be in the 1 column, all those below the diagonal should be in the 0 column. Instances above the diagonal in the 0 column are errors. Instances below the diagonal in the 1 column are errors. Coefficient of reproducibility $=.81$.

least share the task equally. The test for Guttman fit is that at least $90 \%$ of observations must fit this pattern: Those who do the hardest tasks will also do all previous tasks (Nie, Hull, Jenkins, Steinbrenner, \& Bent, 1975). When divided into five separate steps, our data do not fit this pattern. The coefficient of reproducibility is .81. (See Table 3.)

Thus although husbands are far from being equally likely to participate in any female-typed task. they also do not fit a strict pattern of performing all less sex-typed tasks before they move up to more sex-typed ones. The Guttman scale procedure demonstrates that a unidimensional and cumulative dimension that organizes task participation does not exist. However. there may be other similarities and differences that allow different tasks to cluster, as our odds ratio analysis suggests. Factors in individuals and households also may be differentially associated with participation in various tasks.

\section{Characteristics Associated with Differential Participation}

We divide the usual explanations for husbands' participation into two main groups: pragmatic and rational factors and normative ones. In addition, we consider whether, controlling for such general predispositions, there are increased probabilities of participation in specific tasks when husbands participate in other household chores. In Table 4, we report the logistic regression results for two models-one with only the normative and pragmatic predisposing factors and one adding the performance of other tasks to the model.

Looking first at the models containing only pragmatic and normative factors related to husbands' participation in specific tasks (columns 1, 3, 5, 7, and 9 ), we see that the normative factors clearly are more significant than the practical ones for all five specific chores. Role attitudes about the appropriateness of housework for men and women, in general, and conflicting feelings about housework in the particular couple both have highly significant associations with husbands' participation. These associations are strongest for cleaning and generally weakest for grocery shopping. This suggests that there are some differences in the extent of the gendered meaning that each task carries. Husbands' taste for housework is only significant for dishwashing and housecleaning, suggesting a connection to some dirt sensitivity. Seeing housework as enjoyable may mean having a taste for order and cleanliness that is expressed in higher levels of participation in these cleanup chores. Education is only significant for dishwashing. This might indicate that only for this chore. in which so many husbands already participate, are there different normative expectations of participation for men in different social classes. The only task with a statistically significant association with age is grocery shopping. As expected, younger husbands are more likely to shop for groceries than are older husbands.

No practical factor has any significant association with husbands doing dishes, the least sextyped chore. By contrast. the most sex-typed chore, meal preparation, is-surprisingly enough-the one most associated with wives' time in paid work. Wives who work more hours and contribute a higher proportion of the family income have husbands who are more likely to prepare meals. This might indicate that when practical necessity joins with positive normative support to demand husbands' 
Table 4. Logistic Regression of Husband Participation in Each Task on Practical and Rational and Nonrational and Normative Characteristics (B Coefficients)

\begin{tabular}{|c|c|c|c|c|c|c|c|c|c|c|c|}
\hline \multirow[b]{2}{*}{ Variable } & & \multicolumn{2}{|c|}{$\begin{array}{l}\text { Doing } \\
\text { Dishes }\end{array}$} & \multicolumn{2}{|c|}{$\begin{array}{l}\text { Shopping for } \\
\text { Groceries }\end{array}$} & \multicolumn{2}{|c|}{$\begin{array}{l}\text { Cleaning } \\
\text { House }\end{array}$} & \multicolumn{2}{|c|}{$\begin{array}{c}\text { Doing } \\
\text { Laundry }\end{array}$} & \multicolumn{2}{|c|}{$\begin{array}{l}\text { Preparing } \\
\text { Meals } \\
\end{array}$} \\
\hline & & 1 & 2 & 3 & 4 & 5 & 6 & 7 & 8 & 9 & 10 \\
\hline \multicolumn{12}{|l|}{ Tasks } \\
\hline Does dishes & $(=1)$ & - & - & - & - & - & $.89^{* *}$ & - & -.04 & - & $.75^{*}$ \\
\hline Shops for groceries & $(=1)$ & - & .16 & - & .16 & - & -.39 & - & $.61^{*}$ & - & $.68^{*}$ \\
\hline Cleans house & $(=1)$ & - & $.79^{* *}$ & - & $.79^{* *}$ & - & - & - & $1.15^{* *}$ & - & .25 \\
\hline Does laundry & $(=1)$ & - & -.05 & - & -.05 & - & $1.13^{* *}$ & - & - & - & .28 \\
\hline Prepares meals & $(=1)$ & - & $.68^{*}$ & - & $.62^{*}$ & - & .16 & - & .30 & - & - \\
\hline \multicolumn{12}{|l|}{ Rational and pragmatic } \\
\hline Home before 4 p.m. & $(=1)$ & .63 & .66 & .36 & .38 & -.07 & -.08 & -.31 & -.37 & -.00 & -.13 \\
\hline Wife's hours employed & & -.01 & -.01 & -.00 & -.01 & .02 & .02 & $.03^{*}$ & .02 & $.03^{*}$ & $.03^{*}$ \\
\hline $\begin{array}{l}\text { Husband's hours } \\
\text { employed }\end{array}$ & & -.01 & -.01 & -.01 & -.01 & -.01 & -.01 & -.01 & -.00 & .00 & .01 \\
\hline Husband's hours with & & & & & & & & & & & \\
\hline children & & .00 & .00 & $-.02^{*}$ & $-.02^{*}$ & $.02^{*}$ & .02 & -.01 & -.01 & -.00 & .00 \\
\hline $\begin{array}{l}\text { Percentage of family } \\
\text { income provided by w }\end{array}$ & wife & .01 & .01 & .01 & .01 & .01 & .01 & .01 & .00 & $.03^{* *}$ & $.03^{*}$ \\
\hline \multicolumn{12}{|l|}{ Nonrational and normative } \\
\hline Husband's education & & $.33^{* *}$ & $.34^{* *}$ & -.03 & -.03 & .03 & -.02 & .01 & -.02 & -.07 & -.15 \\
\hline Husband's age & & .01 & .01 & $-.02^{*}$ & $-.03^{*}$ & -.03 & -.03 & -.03 & -.01 & -.00 & .01 \\
\hline Husband enjoys & & & & & & & & & & & \\
\hline housework & $(=1)$ & $.41^{*}$ & .32 & .31 & .27 & $.45^{*}$ & .34 & .33 & .17 & .34 & .22 \\
\hline Abstract role attitudes & & $.45^{* *}$ & $.30^{*}$ & $.32^{* *}$ & $.30^{*}$ & $.74^{* *}$ & $.68^{* *}$ & $.26^{*}$ & .04 & $.35^{*}$ & .21 \\
\hline Conflict over housework & & $.49^{* *}$ & $.36^{* *}$ & $.34^{* *}$ & $.27^{*}$ & $.61^{* *}$ & $.48^{* *}$ & $.44^{* *}$ & .28 & $.52^{* *}$ & $.40^{*}$ \\
\hline Constant & & -1.85 & -2.01 & .63 & .73 & -1.56 & -1.83 & -1.62 & -2.37 & -3.78 & -4.68 \\
\hline
\end{tabular}

Note: The odd columns $(1,3.5,7,9)$ exclude controls for participation in other tasks. The even columns $(2,4,6,8,10)$ control for participation in the other tasks.

${ }^{*} p<.05 . \quad{ }^{* *} p<.01$.

participation, even the high gender threshold for meal preparation may be crossed. In effect, we interpret this finding as meaning that the higher the gender threshold, the more compelling the reasons for sharing must be. Time with children is positively associated with housecleaning and negatively with grocery shopping. This suggests that the common factor might be time spent in the home itself. (Time away from home possibly is associated with doing errands such as grocery shopping; time at home is associated with child care and cleaning.)

By now adding the other four tasks to the models for each specific task, we can see both the interrelations among tasks and the extent to which they share a single dimension of association. If role attitudes, for example, have similar associations with dishwashing as with preparing meals, adding dishwashing to the model of participating in meal preparation will add nothing new to the model or will merely reduce the relationship of sex role attitudes to nonsignificance. Conversely, insofar as these tasks are interrelated on some other basis (unmeasured aspects of gender expectations or common features of how the work is structured), they will have significant associations with each other over and above the common relationships with role attitudes (or other variables controlled in the model).

This expanded model is also presented in Table 4 (columns 2, 4, 6, 8, and 10). In the right portion of each column, we see the coefficients for the pragmatic and normative factors when controlling for performance of other tasks on each discrete task. Here, we note that few of the significant relationships in the previous model are eliminated by adding the other tasks to the equations. This suggests that each task has distinct characteristics that link it to the others, over and above their shared variance due to their common associations (such as the significant relationship of role attitudes and conflict over housework). The attitudes factor does drop to nonsignificance for laundry and meals. This suggests that attitudes are related to less participation at lower levels but that for these highly sex-typed chores, the connections are already reflected in participation in tasks with a lower threshold. The relationship between enjoyment of housework and husbands' participation in dirt-removal chores (housecleaning and dishwashing) is no longer significant either. 
The logistic regressions suggest that at least some of what patterns husbands' participation may have to do with believing that certain tasks belong together, over and above beliefs about the gender appropriateness of doing housework at all, feelings about housework, or practical constraints. Both preparing meals and housecleaning are associated with dishwashing: laundry and dishwashing, with housecleaning; dishwashing and grocery shopping, with preparing meals. At least in these cases, an interpretation of shared involvement in a certain domain of work (feeding the family, maintaining cleanliness) does not seem far-fetched.

\section{Discussion}

We offered a model of the division of household labor more analogous to a model of occupational sex segregation, and we found evidence that husbands' participation in core household tasks usually grouped together indiscriminately as female-typed tasks-is patterned. We argued that household tasks are laden with meaning and that to take seriously how the division of labor produces appropriate men and women demands looking at the degree of segregation in and between chores. We examined the relationship among and between these tasks and the characteristics of the husbands who do them, and we found a hierarchy of participation in which more sex-typed chores are added to less-segregated ones. We also found systematic differences in who crosses which gender thresholds, even though we failed to find a single dimension running between all five tasks.

Our results suggest that there is not one, but several, gendered thresholds that some husbands cross to become high participators. At the lowest level, doing dishes appears to be a boundary task that separates men who participate at all from those who do no female sex-typed housework. Grocery shopping is a somewhat similar, entry-level task. At the high end, preparing meals is a chore that relatively few husbands do, but those who do it are also likely to be engaged in a number of other chores. Although cooking may be a highly skilled task that husbands, on average, are less well prepared to do than wives, this does not explain our finding that skilled husbands also are considerably more likely to do the other low-skill chores. Even though meal preparation is skilled work, men do cook when it is defined as gender appropriate (whether as chefs in restaurants or on the backyard grill). Husbands who are able and willing to engage in meal preparation on a regular basis have crossed a gender threshold that defines only women as having or using such skills in the home kitchen. Our research suggests that these men, with a higher probability than other husbands, also participate in other female-gendered chores (such as doing laundry) that require entirely different skills. The hypothesis of a gendered hierarchy of tasks is consistent with this observed pattern. Note that it is only in this most highly gendered task, meal preparation, where wives' work hours and income play a role in whether or not their husbands share the work. Whether or not husbands in such couples have or acquire more cooking skills may be a matter of practical necessity. Only at the other end of the sex-typing continuum, in the least gendered taskdoing dishes-does education matter. Rather than assuming that working-class families are more gender segregated, we might consider how token and substantial forms of gender integration may differ by class. These are results that demand further investigation if they are replicated in other data sets.

Unpacking the meaningful patterns of husbands' participation also means understanding how dimensions other than gender might help structure work in the household. For example, although doing the dishes and preparing meals are at the opposite ends of the sex-type hierarchy of tasks, they are also tasks that are linked, as the regression results demonstrate. These tasks are more related to each other than can be detected from husbands' characteristics alone. If the clustering of tasks that we have identified as the domains of feeding the family and maintaining cleanliness create boundaries around men's and women's gendered responsibilities, change in the division of household labor cannot come without desegregating specific areas of responsibility.

Understanding that tasks reflect a gender hierarchy and are patterned by areas of responsibility should lead us to look more productively at the extent to which specific chores may have changed their sex type over time. Earlier studies. such as those by Fenstermaker Berk (1985) and Robinson (1988). exist, but incommensurabilities in samples and questions make comparisons inconclusive at best and misleading at worst. Evaluating the extent to which the segregation of tasks may have changed over time is important to understanding the underlying structure of gender thresholds and other systematic obstacles to husbands' participation in housework. Have the relative odds of participating in one task rather than in another changed? Are specific tasks gaining or losing gender meaning in ways that cluster them differentially with other household work? For example, was it true in earlier data sets that spending time with children was 
negatively associated with grocery shopping? Has dishwashing been easier for men to share than other chores, even before dishwashers became ubiquitous? Might the relationship between education and participation in dishwashing reflect differences in the likelihood of owning a dishwasher or class-specific cultural issues?

Some researchers have implicitly concluded that some desegregation of household tasks is occurring by their introduction of a gender-neutral category to describe tasks previously categorized as female. What are we to make of the fact that dishwashing, a task often considered female, is a gender-integrated task in our sample? Is dishwashing in an early stage of becoming regendered as male work in the home, like taking out the trash and fixing the car? And if so, what are the implications of such regendering? As with occupational segregation processes, it is important to consider the socioeconomic context in which the gendering of work takes place and, therefore, the meaning of change. With more families having dishwashers and with more take-out food being consumed, the total amount of dishwashing may have declined to the point where soon it may become a trivial amount of work and thus an easy task to regender as a male responsibility without affecting the total amount of work that women do in the home. Dishwashing could turn out to be an enclave for husbands, rather than a port of entry.

Thus, we see two challenges for future research. First, case studies are needed that identify the processes of and obstacles to men's participation in higher-level household chores. Although doing one task significantly increases the likelihood of doing more than one, indicating a positive feedback among them, there also are additional barriers that make doing laundry, for example, harder for husbands than doing dishes. A better model of how doing laundry is organized in relation to other tasks is just as important for understanding the process of gender segregation in the household as studies of specific occupations are for understanding the process of segregation in the paid labor market.

Second, we need reliable, sufficiently disaggregated, over-time measures applied to tasks, rather than time, to assess the change in task segregation that researchers intuitively sense. Counting change in representative samples is, after all, a strength of quantitative research. Without appropriate measures, however, we cannot answer such a seemingly simple question as whether more husbands today are doing the laundry, much less describe changes over time in the relationship between doing laundry and other chores in households with more or less egalitarian values or in households with more or fewer pragmatic constraints. We have argued here that it is important to begin to untangle the processes that might be involved in the desegregation of household tasks. In order to do such research, we need a scholarly consensus on the best measures of what constitutes a sex-typed chore. We have suggested using a cut-off point, but this approach is also limited.

Perhaps the next necessary step to consensus would be a meta-analysis of the multitude of studies of the division of household labor to develop and test a metric for comparing the changing gender structure of core household chores. Such an analysis is particularly needed to revisit and assess the data gathered in early studies and to build their results into a picture of current reality. We share the common intuition that change is going on at some level, and we urge that sharing specific tasks be considered as an important type of change to measure. We have shown that household chores are not and should not be treated as interchangeable widgets, any more than all occupations are alike. There are dimensions of meaning differentiating tasks that quantitative research, as well as qualitative research, can and should probe further.

\section{Note}

This work was conducted with the support of National Science Foundation Grant SES-88-11944, and the government has certain rights in this material. An earlier version of this article was presented at the 1997 annual meeting of the Eastern Sociological Society. The authors thank Sarah Fenstermaker and the anonymous reviewers for Journal of Marriage and the Family for their thoughtful comments on previous versions of the article.

\section{References}

Acker, J. (1990). Hierarchies, jobs, bodies: A theory of gendered organizations. Gender \& Society, 4, 139-158.

Baxter, J. (1992). Power attitudes and time: The domestic division of labour. Journal of Comparative Family Studies, 23, 165-182.

Becker, G. S. (1991). A treatise on the family (Enlarged ed.). Cambridge. MA: Harvard University Press.

Blain, J. (1994). Discourses of agency and domestic labor: Family discourse and gendered practice in dual-earner families. Journal of Family Issues, 15, 515-549.

Blair, S. L., \& Johnson, M. P. (1992). Wives' perceptions of the fairness of the division of household labor: The of housework and ideology. Journal of Marriage and the Family 52, 570-581. 
Blair, S. L., \& Lichter, D. T. (1991). Measuring the division of household labor: Gender segregation of housework among American couples. Journal of Family Issues, 12, 91-113.

Blood. R., \& Wolfe, D. (1960). Husbands and Wives: The dynamics of married living. Glencoe, IL: Free Press.

Brines, J. (1993). The exchange value of housework. Rationality and Society, 5, 302-340.

Cohn, S. (1985). The process of occupational sex-typing: The feminization of clerical labor in Great Britain. Philadelphia: Temple University Press.

Coltrane, S. (1989). Household labor and the routine production of gender. Social Problems, 36, 473-490.

Coltrane, S. (1996). Family man: Fatherhood, housework, and gender equity. New York: Oxford University Press.

Coverman. S. (1985). Explaining husbands' participation in domestic labor. The Sociological Quarterly 26, 181-197.

DeVault, M. (1991). Feeding the family: The social organization of caring as gendered work. Chicago: The University of Chicago Press.

England, P., \& Farkas, G. (1986). Households employment and gender: A social, economic and demographic view. New York: Aldine Publishing.

Fenstermaker Berk, S. F. (1985). The gender factory: The apportionment of work in American households. New York: Plenum Press.

Ferree, M. M. (1990). Beyond separate spheres: Feminism and family research. Journal of Marriage and the Family, 52, 866-885.

Ferree, M. M. (1991). The gender division of labor in twoearner marriages: Dimensions of variability and change. Journal of Family Issues, 12, 158-180.

Fishbein, M., \& Ajzen, I. (1975). Belief, attitude, intention, and behavior: An introduction to theory and research. Reading, MA: Addison-Wesley.

Fraser, N. (1989). Unruly practices: Power, discourse and gender in contemporary social theory. Minneapolis: University of Minnesota Press.

Gerson, J. M., \& Peiss, K. (1985). Boundaries. negotiation. consciousness: Reconceptualizing gender relations. Social Problems, 32, 317-331.

Greenstein, T. N. (1996). Gender ideology and perceptions of the fairness of the division of household labor: Effects on marital quality. Social Forces, 74, 1029-1042.

Hall, E. (1993). Waitering/waitressing: Engendering the work of table servers. Gender \& Society, 7, 329-346.

Hertz, R. (1986). More equal than others: Women and men in dualcareer marriages. Berkeley: University of California Press.

Hochschild, A. (with Machung, A.). (1989). The second shift. New York: Avon Books.

Hood, J. (1983). Becoming a two job family. New York: Praeger.

Huber, J., \& Spitze. G. (1983). Sex stratification: Children, housework and jobs. New York: Academic Press.

Lennon, M. C., \& Rosenfield, S. (1994). Relative fairness and the division of housework: The importance of options. American Journal of Sociology, 2, 506-531.
Mahoney, R. (1995). Kidding ourselves. New York: Basic Books.

McQuillan, J., \& Ferree, M. M. (1997). The importance of variation among husbands and the benefits of feminism for families. In A. Booth (Ed.). Men in families (pp. 213225). Mahwah, NJ: Erlbaum.

Nie, N. H., Hull. C. H., Jenkins, J. G., Steinbrenner, K., \& Bent, D. H. (1975). Statistical package for the social sciences (2nd ed.). New York: McGraw Hill.

Pahl, J, M. (1989). Money and marriage. New York: St. Martin's Press.

Pierce, J. L. (1995). Gender trials. Berkeley: University of California Press.

Potuchek, J. L. (1997). Who supports the family: Gender and breadwinning in dual-earner marriages. Stanford. CA: Stanford University Press.

Presser, H. B. (1994). Employment schedules among dualearner spouses and the division of household labor by gender. American Sociological Review, 59, 348-364.

Reskin, B. F. (1993). Sex segregation in the workplace. Annual Review of Sociology, 19, 241-270.

Reskin, B. F., \& Roos P. A. (1990). Job queues, gender queues: Women's inroads into male occupations. Philadelphia: Temple University Press.

Robinson, J. P. (1988). Who's doing the housework'? American Demographics, 10, 24-28, 63.

Ross, C. (1987). The division of labor at home. Social Forces, $65,816-833$.

Shelton, B. A., \& John, D. (1993). Does marital status make a difference? Housework among married and cohabiting men and women. Journal of Family Issues, 14, 401-420.

South, S. J., \& Spitze, G. (1994). Housework in marital and nonmarital households. American Sociological Review, 59, 327-347.

Spitze, G. (1986). The division of task responsibility in U.S. households: Longitudinal adjustments to change. Social Forces, 64, 689-701.

Staines, G. L., \& Pleck, J. H. (1983). The impact of work schedules on the family. Ann Arbor: Institute for Social Research, University of Michigan, Survey Research Center.

Thompson, L., \& Walker, A. (1989). Gender in families: Women and men in marriage, work and parenthood. Journal of Marriage and the Family, 5, 845-871.

Tichenor, V. (1996). Doing gender in cross-class families: The challenge of constructing an appropriately gendered self in an unconventional marriage. Unpublished paper.

West, C., \& Zimmerman, D. (1987). Doing gender. Gender \& Society, 1, 124-151.

Williams, C. L. (1989). Gender differences at work. Berkeley: University of California Press.

Williams, L. S., \& Villemez, W. J. (1993). Seekers and finders: Male entry and exit in female-dominated jobs. In C. L. Williams (Ed.), Doing "women's work": Men in nontraditional occupations (pp. 64-90). Newbury Park. CA: Sage. 